\title{
Population-based centile curves for triceps, subscapular, and abdominal skinfold thicknesses in Polish children and adolescents - the OLAF study
}

\author{
Maciej Jaworski • Zbigniew Kulaga • Pawel Płudowski • \\ Aneta Grajda • Beata Gurzkowska • \\ Ewelina Napieralska • Anna Świąder • Huiqi Pan • \\ Mieczysław Litwin • the Olaf Study Group
}

Received: 25 January 2012 / Accepted: 29 February 2012 /Published online: 21 March 2012

(C) The Author(s) 2012. This article is published with open access at Springerlink.com

\begin{abstract}
Skinfold thicknesses are used as valid anthropometric indicators of regional body fatness. Actual populationbased values for skinfold thicknesses for Polish children are not available. The purpose of this study was to provide population-
\end{abstract}

The OLAF Study Group: Medical University of Białystok: RybiSzumińska Agnieszka, Szumiński Michał, Taranta-Janusz Katarzyna, Tenderenda Edyta, Wasilewska Anna; Regional Children's Hospital in Bydgoszcz: Jasińska Beata; Medical University of Gdańsk: Czarniak Piotr, Świętoń Dominik, Szcześniak Przemysław; Jagiellonian University Medical College in Kraków: Miklaszewska Monika, Moczulska Anna, Wilkosz Katarzyna, Zachwieja Katarzyna, Ogarek Iwona; Medical University of Lublin: Majewski Marek, Sobieszczańska-Droździel Aleksandra, Szlązak Izabela, Szlązak Paweł, Zajączkowska Małgorzata; Polish Mother's Memorial Hospital Research Institute in Łódź: Pawlak-Bratkowska Monika, PółtorakKrawczyk Anna, Tkaczyk Marcin; District Hospital in KędzierzynKoźle: Gmyrek Danuta; Poznan University of Medical Sciences: Krynicki Tomasz, Sołtysiak Jolanta; Regional Children's Hospital in Toruń: Stankiewicz Roman, Zbucka Sława; The Children's Memorial Health Institute in Warszawa: Pietruczuk Robert, Różdżyńska Agnieszka, Szpor Jan; Wroclaw Medical University: Kleszczyński Jacek, Naleśniak Magdalena, Wawro Anna, Wikiera-Magott Irena, Zwolińska Danuta; Medical University of Silesia: Adamczyk Piotr, Augustyn-Iwachów Tatiana, Banaszak Beata, Bjanid Omar, BrollWaśka Katarzyna, Morawiec-Knysak Aurelia.

M. Jaworski $(\bowtie) \cdot$ P. Płudowski

Department of Biochemistry and Experimental Medicine,

The Children's Memorial Health Institute,

Warsaw, Poland

e-mail: pracownia.densytometria@czd.pl

Z. Kułaga · A. Grajda • B. Gurzkowska • E. Napieralska Public Health Division, The Children's Memorial Health Institute, Warsaw, Poland

\section{A. Świąder}

Anthropology Division, Department of Pediatrics, The Children's Memorial Health Institute,

Warsaw, Poland based values for triceps, subscapular, and abdominal skinfold thicknesses in healthy children and adolescents. A total number of 17,416 boys and girls aged $6.5-18.5$ years, randomly selected from whole Polish population of children and adolescents,
H. Pan

MRC Centre of Epidemiology for Child Health,

UCL Institute of Child Health,

London, UK

M. Litwin

Department of Nephrology and Arterial Hypertension,

The Children's Memorial Health Institute,

Warsaw, Poland

M. Litwin

Department of Research,

The Children's Memorial Health Institute,

Warsaw, Poland 
Table 1 Number of subjects by sex and age

\begin{tabular}{lrr}
\hline Age group years & \multicolumn{2}{l}{ Sex } \\
\cline { 2 - 3 } & \multicolumn{1}{l}{ Female } & Male \\
\hline $6.5-7.5$ & 392 & 454 \\
$7.5-8.5$ & 701 & 729 \\
$8.5-9.5$ & 703 & 742 \\
$9.5-10.5$ & 753 & 658 \\
$10.5-11.5$ & 683 & 672 \\
$11.5-12.5$ & 642 & 641 \\
$12.5-13.5$ & 657 & 646 \\
$13.5-14.5$ & 775 & 678 \\
$14.5-15.5$ & 730 & 735 \\
$15.5-16.5$ & 829 & 700 \\
$16.5-17.5$ & 1,075 & 813 \\
$17.5-18.5$ & 1,155 & 853 \\
Sub-total & 9,095 & 8,321 \\
Total & 17,416 & \\
\hline
\end{tabular}

Table 2 Characteristic of studied group

\begin{tabular}{|c|c|c|c|c|c|c|}
\hline & \multicolumn{3}{|l|}{ Female } & \multicolumn{3}{|l|}{ Male } \\
\hline & Median & Min. & Max. & Median & Min. & Max. \\
\hline Height $(\mathrm{cm})$ & 157.9 & 106.7 & 185.0 & 158.8 & 109.8 & 200.1 \\
\hline Weight $(\mathrm{kg})$ & 47.6 & 14.2 & 119.6 & 48.4 & 16.0 & 128.0 \\
\hline $\begin{array}{l}\text { Body mass } \\
\text { index }\left(\mathrm{kg} / \mathrm{m}^{2}\right)\end{array}$ & 18.9 & 11.6 & 46.3 & 18.8 & 11.9 & 45.1 \\
\hline
\end{tabular}

were enrolled in the study. Skinfold thicknesses (triceps, subscapular, and abdominal) were measured using Harpenden skinfold caliper. All measurements were taken after the training of participating investigators. The $L M S$ method was used to fit percentile curves across age for each skinfold. $Q$ tests for fit were used to assess the global goodness of fit of our final models. The study shows for the first time smoothed populationbased values of body fat distribution indices for Polish children and adolescents $7-18$ years of age. Reported skinfold centiles are higher compared to previously established for Warsaw children and very close to the actual US data. Conclusion Our study provided for the first time population-based values for skinfold thicknesses evaluation in a way allowing to calculate reliable $Z$ scores. The early detection of abnormal fat stores, using our population-based values and respective $Z$ scores, may be now implemented for practice.

Keywords Triceps $\cdot$ Subscapular $\cdot$ Abdominal skinfold thickness $\cdot$ Population-based values $\cdot$ Children $\cdot$ Polish

\section{Introduction}

Skinfold thicknesses evaluation, due to its low cost and noninvasive procedure, is one of the most widely used anthropometric methods for assessment of nutritional status during growth and maturation period [7, 10, 23, 25]. Excess fat, as assessed using skinfold thicknesses, is associated with abnormal concentrations of triglycerides, increased low-density lipoprotein cholesterol, reduced high-density lipoprotein cholesterol, and insulin resistance; all factors markedly increasing risk for hypertension, metabolic syndrome, and cardiovascular disease $[8,21]$.

Skinfold measurements have low precision error but should be done by well-trained personnel [23]. In practice, the magnitude of precision error largely depends on the skills of examiner conducting examinations, however is low compared to variability observed between subject [24, 25]. Skinfold thickness assessments are also utilized to identify individual body somatotype, enabling estimations of body density and lean body mass [14, 22, 25]. a

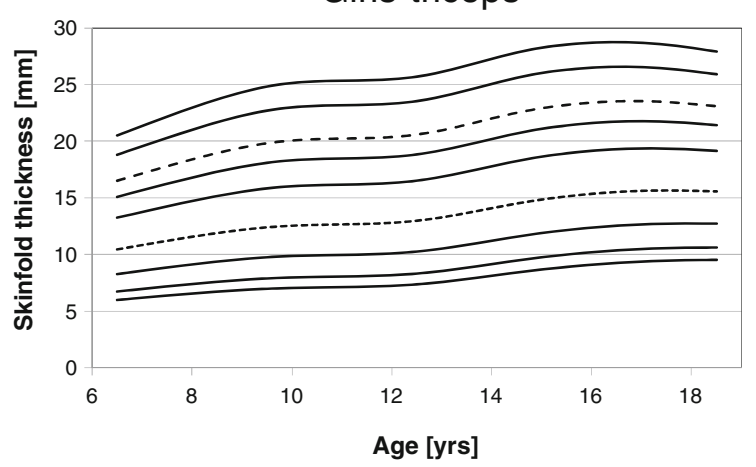

Boys-triceps

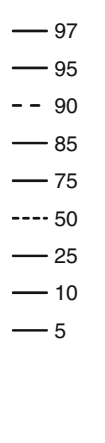

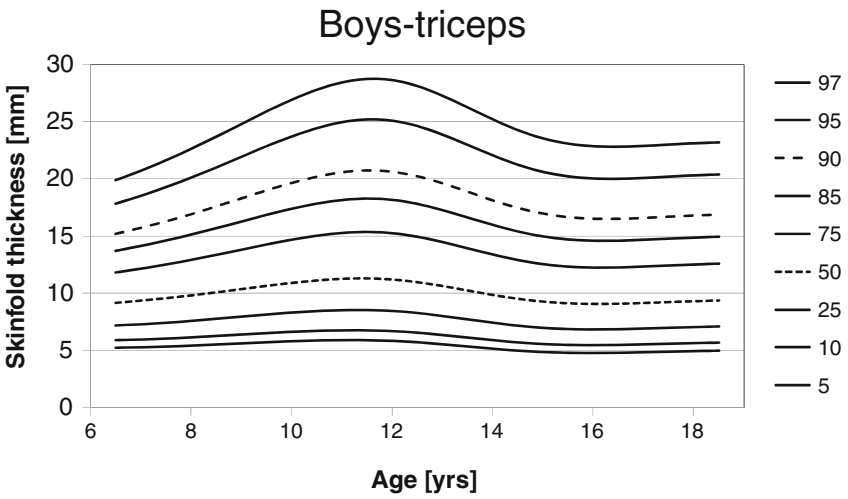

Fig. 1 Smoothed percentile curves for skinfold thicknesses for boys and girls across age. Dotted line (median) and dashed line (90th percentile) were used for better readability 
b

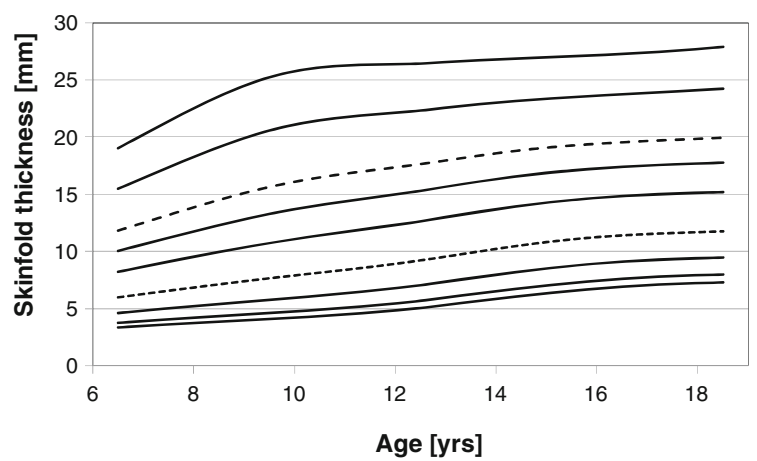

Fig. 1 (continued)

Reliable determination of references (medians and percentiles) for a given skinfold thicknesses requires a large set of healthy subjects [1]. Previous methodologies used empirical percentiles according to sex and age groups. Recently, the reference values based on smoothed curves across the age groups are favored. The most preferred method to establish references is LMS method. Box-Cox transformation allows transformation of data to normality by a suitable power transformation. Standardized $Z$ scores can be calculated from transformed data $[4,5]$.

Actual population-based references for skinfold thicknesses are not available for Polish children, and local data are limited to urban regions, including the cities of Warsaw and Cracow $[2,18]$. Further, the data from Warsaw study were collected more than a decade ago, comprised only children living in the city area, and reference data were developed using outdated statistical procedures that not allowed to calculate $Z$ scores. The references from Cracow study were collected 9 years ago and as well as in Warsaw comprised only urban children. Although, the Cracow data were established by $L M S$ method, Box-Cox transformation power ( $L$ value), median $(M)$, and generalized coefficient of variation ( $S$ value) were not published; therefore, calculation of $Z$ scores was not available. Since skinfold thickness evaluation is still considered as useful method for assessment of nutritional status during growth and because actual and appropriately established references are missing for Polish population, the purpose of this study was to provide population-based values for triceps, subscapular, and abdominal skinfold thicknesses for children and adolescents aged $7-18$ years.

\section{Material and methods}

Population

The analyzed data were collected in the course of the OLAF study in which the reference blood pressure ranges were

\section{Boys-subscapular}

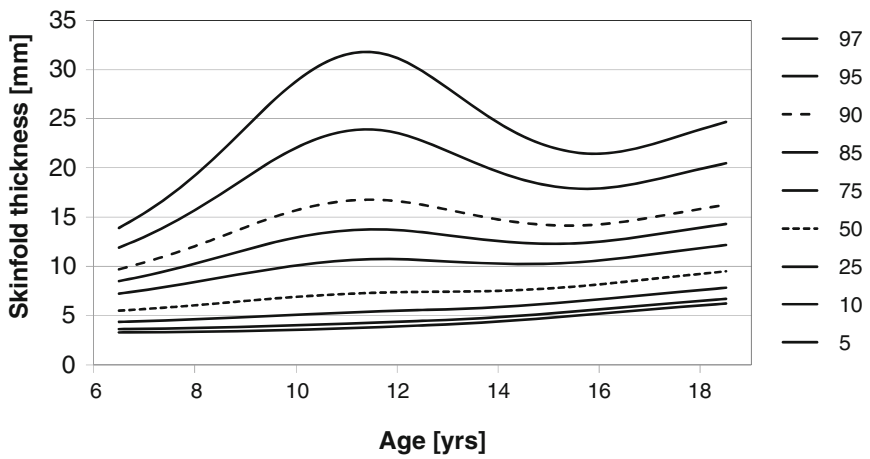

elaborated for Polish children and adolescents. The study sample comprised data collected between November 2007 and November 2009. Study participants were randomly selected using two-stage sampling. Primary units (schools) were sampled from an all-schools-in-Poland sampling frame; sampling was stratified by urban/rural area. In the second stage, all pupils in the required age range within the sampled schools comprised the sampling frame. Pupils in schools were selected for the survey by stratified random sampling, the stratification variables being classes. The medical history of the study participants, including past and present diseases, as well as medications used, was taken from the parents. The general health status of each subject was assessed by a physician. Exclusion criteria was as follows: infection with diarrhea leading dehydration, absence of right upper limb or phocomelia, dwarfism, cachexia, Cushing syndrome, renal failure, heart failure, hepatic failure, etc., organ transplantation, systemic diseases, malignant cancer, Turner syndrome, Down syndrome, etc., systemic glucocorticoids use, and pregnancy.

All subjects and their parents (in the case of subjects under 18 years of age) gave their informed consent to participate in the study (subjects over 16 years of age and parents gave written consent). Ethical approval was obtained from Ethical Committee of The Children's Memorial Health Institute before the study commenced.

A total number of 17,416 boys and girls aged 6.518.5 years with measured at least one skinfold thickness were enrolled in the study. The response rate was 0.71 . We excluded small number of outliers ( 7 for triceps, 21 for abdominal, and 13 for subscapular) following \pm 5 standard deviation criteria as was done by other authors $[1,11]$. Characteristics of studied group were presented in Tables 1 and 2.

Measurements

The OLAF study (PL0080) was carried out in 416 schools (325 cities, countries, and villages) covering all regions of 
C

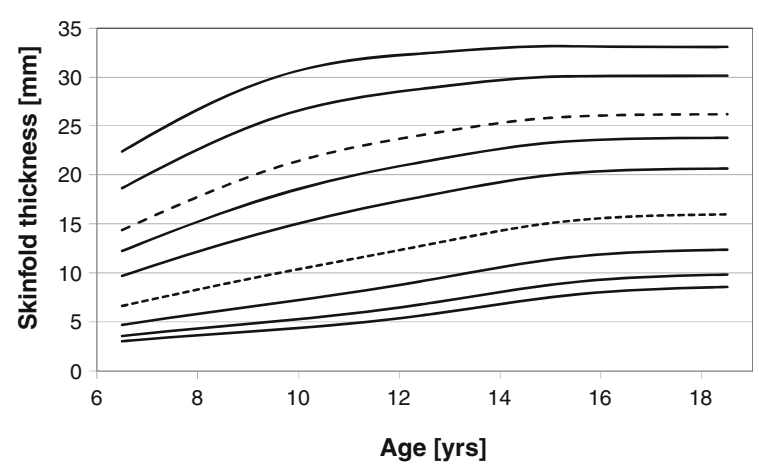

Fig. 1 (continued)

Poland. Measurements were conducted in school nurses' offices from 8:00 a.m. to 3:00 p.m.; room temperature was in range $20-26^{\circ} \mathrm{C}$. All measurements were taken by centrally trained staff: anthropologists, nurses, public health professionals, and physicians using the standard and calibrated equipment from the same manufacturer.

Body height was measured in the standing position using stadiometer (SECA 214). Body weight was measured using medical scale (Radwag WPT 100/200). Body mass index was calculated as body weight divided by height in meters squared. The exact age of each participant was calculated from birth and observation dates.

Skinfold thickness measurements were performed by lifting a fold of skin and subcutaneous fat away from the underlying muscle and bone. Each skinfold thickness was measured in duplicate with Harpenden skinfold caliper. When a difference between the first and the second measurement exceeded $6 \mathrm{~mm}$, a third measurement was taken. The triceps skinfold was lifted parallel to the long axis of the body, midway on the back of the hanging freely right upper arm. The subscapular skinfold was lifted horizontally below the tip of right scapula. The abdominal skinfold was lifted diagonal midway between umbilicus and right anterior superior iliac spine.

All measurements were taken by centrally trained staff. The training consisted of workshops for study teams, during which the standardized measuring technique was presented (lecture, visuals) and taught (practical exercises). Following the workshop, in-the-field standardization sessions were conducted according to the standardization protocol. Reliability of skinfold thickness measurements between the trainer and the study staff was recorded. After 10 months of conducting the study, re-training of study teams was carried out.

\section{Boys-abdominal}

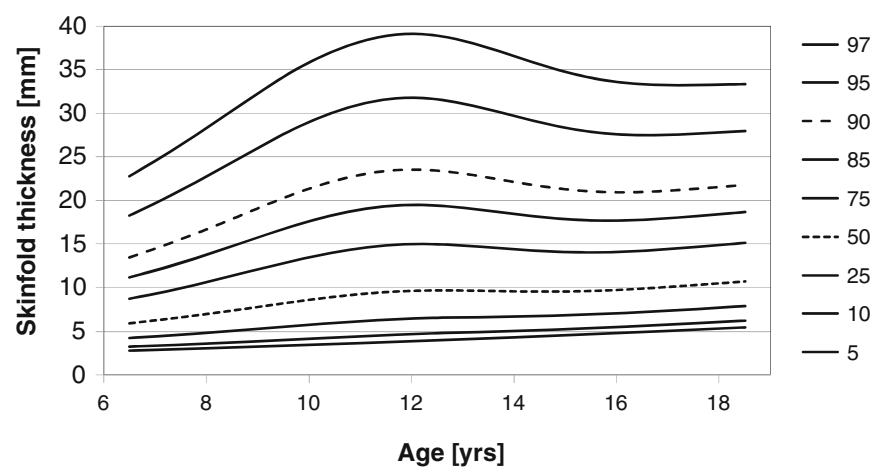

Statistics

The LMS method [4] was used to fit percentile curves across age for each skinfold. LMSchartmaker v. 2.43 (Medical Research Council, UK) [20] was used to derive the smoothed percentiles. The LMS method uses polynomial splines to fit smoothed curves: $L$ (Box-Cox transformation power), $M$ (median), and $S$ (generalized coefficient of variation) across age by maximized penalized likelihood [5]. The smoothed percentile estimates and the $L, M$, and $S$ parameters were derived from raw data, separately for each skinfold and sex, in a single-stage modeling. $Q$ tests for fit [19] were used to assess the global goodness of fit of our final models.

\section{Results}

The smoothed percentiles for triceps, subscapular, and abdominal skinfold thicknesses are presented in Fig. 1 for boys and girls, separately. In girls, median for triceps skinfold thickness increased from $10.4 \mathrm{~mm}$ (6.5 years) to $15.6 \mathrm{~mm}$ (18.5 years) with plateau between 10 and 12 years and maximum $(15.6 \mathrm{~mm})$ at age 17.5 years. Ninety-seventh percentile increased from $20.5 \mathrm{~mm}$ at age 6.5 years to 27.9 at age 18.5 years with maximum $(28.7 \mathrm{~mm})$ at age 16.5 years. Plateau occurred between 10.5 and 12.0 years. Median for subscapular skinfold thickness increased from 10.0 to $11.8 \mathrm{~mm}$ for 6.5 and 18.5 years, respectively, and 97 th percentile increased from 19.0 to $27.9 \mathrm{~mm}$ for the same ages. Median abdominal skinfold thickness increased from $6.6 \mathrm{~mm}$ (6.5 years) to $16.0 \mathrm{~mm}$ (18.5 years), and 97th percentile increased from 22.4 to $33.0 \mathrm{~mm}$ for the corresponding ages, respectively.

In boys, age-dependent changes and shape of percentile curves were more complex. Local maximums at age 11- 
Table $3 L M S$ parameters for triceps skinfold thickness by sex and age and equivalent degrees of freedom

\begin{tabular}{|c|c|c|c|c|c|c|}
\hline \multirow[t]{2}{*}{ Age } & \multicolumn{3}{|l|}{ Girls } & \multicolumn{3}{|l|}{ Boys } \\
\hline & $L(\operatorname{edf} 1)$ & $M($ edf 6$)$ & $S(\operatorname{edf} 3)$ & $L($ edf 1$)$ & $M($ edf 6$)$ & $S$ (edf 3) \\
\hline 6.5 & -0.07824 & 10.451 & 0.3492 & -0.3034 & 9.146 & 0.3676 \\
\hline 7.0 & -0.07824 & 10.836 & 0.3510 & -0.3034 & 9.346 & 0.3758 \\
\hline 7.5 & -0.07824 & 11.209 & 0.3529 & -0.3034 & 9.562 & 0.3840 \\
\hline 8.0 & -0.07824 & 11.566 & 0.3547 & -0.3034 & 9.806 & 0.3922 \\
\hline 8.5 & -0.07824 & 11.893 & 0.3564 & -0.3034 & 10.076 & 0.4000 \\
\hline 9.0 & -0.07824 & 12.177 & 0.3578 & -0.3034 & 10.361 & 0.4075 \\
\hline 9.5 & -0.07824 & 12.401 & 0.3589 & -0.3034 & 10.647 & 0.4143 \\
\hline 10.0 & -0.07824 & 12.543 & 0.3596 & -0.3034 & 10.906 & 0.4203 \\
\hline 10.5 & -0.07824 & 12.617 & 0.3596 & -0.3034 & 11.122 & 0.4252 \\
\hline 11.0 & -0.07824 & 12.660 & 0.3590 & -0.3034 & 11.269 & 0.4292 \\
\hline 11.5 & -0.07824 & 12.707 & 0.3578 & -0.3034 & 11.308 & 0.4321 \\
\hline 12.0 & -0.07824 & 12.799 & 0.3558 & -0.3034 & 11.208 & 0.4341 \\
\hline 12.5 & -0.07824 & 12.985 & 0.3532 & -0.3034 & 10.976 & 0.4353 \\
\hline 13.0 & -0.07824 & 13.280 & 0.3500 & -0.3034 & 10.639 & 0.4357 \\
\hline 13.5 & -0.07824 & 13.665 & 0.3462 & -0.3034 & 10.244 & 0.4354 \\
\hline 14.0 & -0.07824 & 14.090 & 0.3421 & -0.3034 & 9.847 & 0.4347 \\
\hline 14.5 & -0.07824 & 14.498 & 0.3377 & -0.3034 & 9.508 & 0.4336 \\
\hline 15.0 & -0.07824 & 14.848 & 0.3332 & -0.3034 & 9.258 & 0.4322 \\
\hline 15.5 & -0.07824 & 15.130 & 0.3286 & -0.3034 & 9.110 & 0.4306 \\
\hline 16.0 & -0.07824 & 15.353 & 0.3241 & -0.3034 & 9.056 & 0.4290 \\
\hline 16.5 & -0.07824 & 15.518 & 0.3197 & -0.3034 & 9.074 & 0.4275 \\
\hline 17.0 & -0.07824 & 15.618 & 0.3155 & -0.3034 & 9.136 & 0.4260 \\
\hline 17.5 & -0.07824 & 15.649 & 0.3113 & -0.3034 & 9.216 & 0.4245 \\
\hline 18.0 & -0.07824 & 15.623 & 0.3072 & -0.3034 & 9.292 & 0.4232 \\
\hline 18.5 & -0.07824 & 15.569 & 0.3031 & -0.3034 & 9.358 & 0.4218 \\
\hline
\end{tabular}

$L$ Box-Cox transformation power, $M$ median, $S$ generalized $\mathrm{CV}$, edf equivalent degrees of freedom

12 years occurred for most of the percentiles of all skinfold thicknesses. For triceps skinfold thickness median increased from $9.2 \mathrm{~mm}$ (6.5 years) to $11.3 \mathrm{~mm}$ (11.5 years), then decreased to $9.1 \mathrm{~mm}$ (16.0 years), and then slightly increased to $9.4 \mathrm{~mm}$ at age 18.5 years. Ninety-seventh percentile increased from $19.9 \mathrm{~mm}$ (6.5 years) to $28.8 \mathrm{~mm}$ (11.5 years), then decreased to $22.8 \mathrm{~mm}$ (16.5 years), and then slightly increased to $23.2 \mathrm{~mm}$ at age 18.5 years. For subscapular skinfold thickness, median increased from $5.5 \mathrm{~mm}$ (6.5 years) to $9.5 \mathrm{~mm}$ (18.5 years), whereas 97 th percentile increased from $13.9 \mathrm{~mm}$ (6.5 years) to $31.8 \mathrm{~mm}$ (11.5 years), then decreased to $21.4 \mathrm{~mm}$ (16.0 years), and then increased to $24.7 \mathrm{~mm}$ (18.5 years). For abdominal skinfold thickness, median increased from $5.9 \mathrm{~mm}$ (6.5 years) to $9.7 \mathrm{~mm}$ (12.5 years), then very slightly decreased to $9.5 \mathrm{~mm}$ (14.5 years), and then increased to $10.7 \mathrm{~mm}$ at age 18.5 years. Ninety-seventh percentile
Table 4 LMS parameters for subscapular skinfold thickness by sex and age and equivalent degrees of freedom

\begin{tabular}{|c|c|c|c|c|c|c|}
\hline \multirow[t]{2}{*}{ Age } & \multicolumn{3}{|l|}{ Girls } & \multicolumn{3}{|l|}{ Boys } \\
\hline & $L(\operatorname{edf} 3)$ & $M($ edf 5) & $S(\operatorname{edf} 4)$ & $L(\operatorname{edf} 3)$ & $M($ edf 6$)$ & $S$ (edf \\
\hline 6.5 & -0.6912 & 5.955 & 0.4249 & -0.6445 & 5.493 & 0.3712 \\
\hline 7.0 & -0.6748 & 6.249 & 0.4313 & -0.6382 & 5.663 & 3932 \\
\hline 7.5 & -0.6581 & 6.538 & 0.4377 & -0.6322 & 5.845 & .4153 \\
\hline 8.0 & -0.6412 & 6.821 & 0.4437 & -0.6270 & 6.045 & 0.4373 \\
\hline 8.5 & -0.6241 & 7.099 & 0.4491 & -0.6232 & 6.263 & 0.4581 \\
\hline 9.0 & -0.6068 & 7.370 & 0.4534 & -0.6216 & 6.490 & 0.4767 \\
\hline 9.5 & -0.5901 & 7.632 & 0.4560 & -0.6224 & 6.710 & .4917 \\
\hline 10.0 & -0.5745 & 7.883 & 0.4567 & -0.6263 & 6.903 & 0.5019 \\
\hline 10.5 & -0.5606 & 8.128 & 0.4551 & -0.6340 & 7.066 & 0.5068 \\
\hline 11.0 & -0.5490 & 8.374 & 0.4513 & -0.6460 & 7.204 & 0.5060 \\
\hline 11.5 & -0.5401 & 8.630 & 0.4456 & -0.6624 & 7.312 & 0.4994 \\
\hline 12.0 & -0.5344 & 8.907 & 0.4379 & -0.6829 & & 0.4874 \\
\hline 12.5 & -0.5323 & 9.211 & 0.4289 & -0.7069 & 7.414 & 0.4710 \\
\hline 13.0 & -0.5339 & 9.540 & 0.4190 & -0.7337 & 7.434 & 0.4515 \\
\hline 13.5 & -0.5391 & 9.881 & 0.4087 & -0.7627 & 7.464 & 0.4302 \\
\hline 14.0 & -0.5475 & 10.216 & 0.3983 & -0.7929 & 7.520 & 0.4083 \\
\hline 14.5 & -0.5588 & 10.532 & 0.3881 & -0.8233 & 7.620 & 0.3874 \\
\hline 15.0 & -0.5723 & 10.813 & 0.3786 & -0.8532 & 7.764 & 0.3687 \\
\hline 15.5 & -0.5873 & 11.052 & 0.3702 & -0.8821 & 7.951 & 0.3530 \\
\hline 16.0 & -0.6034 & 11.249 & 0.3632 & -0.9098 & 8.180 & 0.3412 \\
\hline 16.5 & -0.6203 & 11.404 & 0.3578 & -0.9364 & 8.443 & 0.3335 \\
\hline 17.0 & -0.6377 & 11.521 & 0.3538 & -0.9619 & 8.717 & 0.3292 \\
\hline 17.5 & -0.6556 & 11.611 & 0.3506 & -0.9866 & 8.985 & 0.3268 \\
\hline 18.0 & -0.6739 & 11.688 & 0.3480 & -1.0109 & 9.248 & 0.3246 \\
\hline 18.5 & -0.6925 & 11.763 & 0.3454 & -1.0350 & 9.511 & 0.3222 \\
\hline
\end{tabular}

$L$ Box-Cox transformation power, $M$ median, $S$ generalized $\mathrm{CV}$, edf equivalent degrees of freedom

increased from 22.8 (6.5 years) to $39.1 \mathrm{~mm}$ (12.0 years) and then decreased to $33.3 \mathrm{~mm}$ at age 18.5 years. Smoothed LMS parameters across age for all measured skinfold thicknesses by sex are shown in Tables 3, 4, and 5 .

\section{Discussion}

This study is the first and the largest study of skinfold thicknesses based on a randomly selected sample of 17,416 boys and girls aged $6.5-18.5$ years from both urban and rural areas of Poland. The study enabled to calculate and provide a reference data for skinfold thicknesses, as noninvasive estimators of fat stores in Polish children and adolescents aged $7-18$ years.

As expected, our results revealed gender-related differences between boys and girls for triceps, subscapular, and 
Table $5 L M S$ parameters for abdominal skinfold thickness by sex and age and equivalent degrees of freedom

\begin{tabular}{|c|c|c|c|c|c|c|}
\hline \multirow[t]{2}{*}{ Age } & \multicolumn{3}{|l|}{ Girls } & \multicolumn{3}{|l|}{ Boys } \\
\hline & $L(\operatorname{edf} 3)$ & $M($ edf 5$)$ & $S($ edf 4$)$ & $L(\operatorname{edf} 4)$ & $M($ edf 5) & $S($ edf 4$)$ \\
\hline 6.5 & -0.3106 & 6.629 & 0.5389 & -0.4553 & 5.902 & 0.5367 \\
\hline 7.0 & -0.2791 & 7.191 & 0.5422 & -0.4239 & 6.241 & 0.5525 \\
\hline 7.5 & -0.2475 & 7.750 & 0.5454 & -0.3930 & 6.591 & 0.5685 \\
\hline 8.0 & -0.2159 & 8.301 & 0.5481 & -0.3629 & 6.964 & 0.5842 \\
\hline 8.5 & -0.1845 & 8.841 & 0.5502 & -0.3345 & 7.359 & 0.5991 \\
\hline 9.0 & -0.1537 & 9.371 & 0.5510 & -0.3092 & 7.773 & 0.6122 \\
\hline 9.5 & -0.1243 & 9.886 & 0.5499 & -0.2876 & 8.190 & 0.6227 \\
\hline 10.0 & -0.0970 & 10.382 & 0.5463 & -0.2703 & 8.588 & 0.6298 \\
\hline 10.5 & -0.0722 & 10.868 & 0.5401 & -0.2588 & 8.947 & 0.6331 \\
\hline 11.0 & -0.0503 & 11.352 & 0.5312 & -0.2548 & 9.250 & 0.6326 \\
\hline 11.5 & -0.0313 & 11.838 & 0.5199 & -0.2592 & 9.478 & 0.6282 \\
\hline 12.0 & -0.0155 & 12.328 & 0.5066 & -0.2713 & 9.615 & 0.6201 \\
\hline 12.5 & -0.0029 & 12.826 & 0.4919 & -0.2897 & 9.668 & 0.6088 \\
\hline 13.0 & 0.0063 & 13.328 & 0.4766 & -0.3125 & 9.658 & 0.5952 \\
\hline 13.5 & 0.0123 & 13.825 & 0.4614 & -0.3379 & 9.613 & 0.5799 \\
\hline 14.0 & 0.0153 & 14.301 & 0.4466 & -0.3639 & 9.563 & 0.5639 \\
\hline 14.5 & 0.0157 & 14.731 & 0.4327 & -0.3884 & 9.537 & 0.5480 \\
\hline 15.0 & 0.0138 & 15.089 & 0.4203 & -0.4100 & 9.549 & 0.5330 \\
\hline 15.5 & 0.0102 & 15.369 & 0.4097 & -0.4271 & 9.607 & 0.5197 \\
\hline 16.0 & 0.0050 & 15.579 & 0.4011 & -0.4385 & 9.717 & 0.5086 \\
\hline 16.5 & -0.0016 & 15.732 & 0.3947 & -0.4439 & 9.875 & 0.4996 \\
\hline 17.0 & -0.0092 & 15.834 & 0.3900 & -0.4444 & 10.066 & 0.4926 \\
\hline 17.5 & -0.0174 & 15.896 & 0.3866 & -0.4412 & 10.271 & 0.4871 \\
\hline 18.0 & -0.0260 & 15.939 & 0.3840 & -0.4358 & 10.483 & 0.4825 \\
\hline 18.5 & -0.0349 & 15.979 & 0.3816 & -0.4295 & 10.698 & 0.4781 \\
\hline
\end{tabular}

$L$ Box-Cox transformation power, $M$ median, $S$ generalized $\mathrm{CV}$, edf equivalent degrees of freedom

abdominal skinfold thicknesses. In girls, percentile curves showed constant increase with age. In boys, subscapular, triceps, and abdominal skinfold thicknesses also increased with age; however, in contrast to girls, maximum values were noted in groups aged 11-12 year and then skinfold thicknesses returned to the values preceding the pubertal spurt. The same finding was already reported in previous studies from Warsaw [18], Cracow [2], and in other populations; however, the phenomenon was mostly evident for triceps skinfold thickness and in less extent for subscapular and abdominal skinfolds [1, 6, 9, 15-17]. Further, our study showed higher percentile and median values than previously reported in Warsaw [18] and Cracow studies [2]. The highest differences were observed for 97th percentile and ranged from 4 to $18 \mathrm{~mm}$ for peaks of skinfold thicknesses and from 2 to $13 \mathrm{~mm}$ for minimums. The increased skinfold thicknesses observed in our study highly likely reflected a secular trend in obesity noted during the last decades in Polish population $[3,12]$.

Furthermore, skinfold thicknesses noted in our study appeared higher than in Dutch [9] and Turkish [17] population. However, the Dutch study was conducted in years 1979-1980, when secular trends in obesity were considered as not very evident [9]. Although the Turkish data were collected in 2005 year, the study comprised population with very low prevalence of obesity [17]. To our knowledge, the highest normal skinfold thicknesses so far reported in literature were established in a representative sample of Spanish adolescents aged 13-18 years [16]. Nationally representative percentiles for US children and adolescents presented only slightly lower values $[1,6,15]$ than Spanish data. Our study results appeared similar to US data.

The main limitation of our study is related to its crosssectional design. Body fat indices in growing children should be rather obtained in longitudinal studies showing longitudinal changes in individual growth and development.

The strength of our study was that examined data were sampled in a random manner from whole population of Polish children and adolescents. Further, intra-observer as well as inter-observer measurement errors were considered as low and satisfactory (data not shown due to large number of investigators participating in this survey), and collected data were verified and checked for outliers. Moreover, the total number of subjects (17,416 boys and girls) allowed reliable determination of medians and percentiles [1, 4]. Finally, our data based on a nationally representative sample of Polish children and adolescents enabled for the first time precise evaluation of skinfold thicknesses using $Z$ scores. In agreement with others $[4,13]$, we strongly recommend the calculation of $Z$ scores corresponding to the percentile rankings, using the following formula: $Z=\{(\operatorname{skt} / M) L-1\} / L S$, where skt indicates actual skinfold thickness. In the case of $L=0$, as noted for abdominal skinfold thickness in girls (Tables 3, 4, and 5), $Z$ score value should be calculated as: $Z=\log (\mathrm{skt} / M) / S$. The last formula should be also used for $L$ between -0.01 and +0.01 [4].

In conclusion, our study based on randomly selected sample of 17,416 healthy children and adolescents from Poland provide for the first time population-based values for skinfold thicknesses evaluation in a way allowing to calculate reliable $Z$ scores. In consequence, the early detection of abnormal fat stores, using our data and respective $Z$ scores, may be now implemented for everyday clinical practice.

Acknowledgments The OLAF study was supported by a grant from Iceland, Liechtenstein, and Norway through the EEA Financial Mechanism and the Norwegian Financial Mechanism and a grant from the Ministry of Science and Higher Education of Poland (no. PL0080). 
Conflict of interest The authors declare that they have no conflict of interest.

Open Access This article is distributed under the terms of the Creative Commons Attribution License which permits any use, distribution, and reproduction in any medium, provided the original author(s) and the source are credited.

\section{References}

1. Addo OY, Himes JH (2010) Reference curves for triceps and subscapular skinfold thicknesses in US children and adolescents. Am J Clin Nutr 91(3):635-642

2. Chrzanowska M, Gołąb S, Żarów R, Sobiecki J, Brudecki J (2002) The child of Cracow 2000. The level of the biological development in the Cracow children and youth. University School of Physical Education in Cracow, Cracow

3. Chrzanowska M, Koziel S, Ulijaszek SJ (2007) Changes in BMI and the prevalence of overweight and obesity in children and adolescents In Cracow, Poland, 1971-2000. Econ Hum Biol 5(3):370-378

4. Cole TJ (1990) The LMS method for constructing normalized growth standards. Eur J Clin Nutr 44(1):45-60

5. Cole TJ, Green PJ (1992) Smoothing reference centile curves: the LMS method and penalized likelihood. Stat Med 11:1305-1319

6. Cronk CE, Roche AF (1982) Race- and sex-specific reference data for triceps and subscapular skinfolds and weight/stature. Am J Clin Nutr 35(2):347-354

7. Fichna P, Skowrońska B (2008) Obesity and metabolic syndrome in children and youth. Family Med Primary Care Rev 2:269-278

8. Freedman DS, Serdula MK, Srinivasan SR, Berenson GS (1999) Relation of circumferences and skinfold thicknesses to lipid and insulin concentrations in children and adolescents: the Bogalusa Heart Study. Am J Clin Nutr 69(2):308-317

9. Gerver WJ, de Bruin R (1996) Body composition in children based on anthropometric data. A presentation of normal values. Eur $\mathrm{J}$ Pediatr 155(10):870-876

10. Goodpaster BH (2002) Measuring body fat distribution and content in humans. Curr Opin Clin Nutr Metab Care 5(5):481-487

11. Katzmarzyk PT (2004) Waist circumference percentiles for Canadian youth 11-18 years of age. Eur J Clin Nutr 58(7):1011-1015

12. Kułaga Z, Litwin M, Tkaczyk M, Palczewska I, Zajączkowska M, Zwolińska D, Krynicki T, Wasilewska A, Moczulska A, MorawiecKnysak A, Barwicka K, Grajda A, Gurzkowska B, Napieralska E, Pan H (2011) Polish 2010 growth references for school-aged children and adolescents. Eur J Pediatr 170(5):599-609

13. Kulaga Z, Litwin M, Tkaczyk M, Rózdzyńska A, Barwicka K, Grajda A, Swiader A, Gurzkowska B, Napieralska E, Pan H (2010) The height-, weight-, and BMI-for-age of Polish school-aged children and adolescents relative to international and local growth references. BMC Publ Health 4(10):109

14. L'Abée C, Visser GH, Liem ET, Kok DE, Sauer PJ, Stolk RP (2010) Comparison of methods to assess body fat in non-obese six to seven-year-old children. Clin Nutr 29(3):317-322

15. McDowell MA, Fryar CD, Ogden CL, Flegal KM (2008) Anthropometric reference data for children and adults: United States, 2003 2006. National Health Statistics Reports Number 10; October 22. http://www.cdc.gov/nchs/data/nhsr/nhsr010.pdf. Accessed 3 Mar 2011

16. Moreno LA, Mesana MI, González-Gross M, Gil CM, Ortega FB, Fleta J, Wärnberg J, León J, Marcos A, Bueno M (2007) Body fat distribution reference standards in Spanish adolescents: the AVENA Study. Int J Obes 31(12):1798-1805

17. Ozturk A, Budak N, Cicek B, Mazicioglu MM, Bayram F, Kurtoglu S (2009) Cross-sectional reference values for midupper arm circumference, triceps skinfold thickness and arm fat area of Turkish children and adolescents. Int J Food Sci Nutr 60(4):267-281

18. Palczewska I, Niedzwiedzka Z (2001) Somatic development indices in children and youth of Warsaw. Med Wieku Rozwoj 5(Suppl 1):18-118

19. Pan H, Cole TJ (2004) A comparison of goodness of fit tests for age-related reference ranges. Stat Med 23:1749-1765

20. Pan H, Cole TJ (2011) LMSchartmaker, a program to construct growth references using the LMS method. Version 2.43. http:// www.healthforallchildren.co.uk. Accessed 15 Dec 2011

21. Steinberger J, Daniels SR, Eckel RH, Hayman L, Lustig RH, McCrindle B, Mietus-Snyder ML (2009) American Heart Association Atherosclerosis, Hypertension, and Obesity in the Young Committee of the Council on Cardiovascular Disease in the Young; Council on Cardiovascular Nursing; and Council on Nutrition, Physical Activity, and Metabolism. Progress and challenges in metabolic syndrome in children and adolescents: a scientific statement from the American Heart Association Atherosclerosis, Hypertension, and Obesity in the Young Committee of the Council on Cardiovascular Disease in the Young; Council on Cardiovascular Nursing; and Council on Nutrition, Physical Activity, and Metabolism. Circulation 119(4):628-647

22. Suliga E (2006) Anthropometrical methods of assessing the nutritional status of children and adolescents. Pediatr Pol 81(10):739746

23. Wagner DR, Heyward VH (1999) Techniques of body composition assessment: a review of laboratory and field methods. Res Q Exerc Sport 70(2):135-149

24. Wang J, Thornton JC, Kolesnik S, Pierson RN (2000) Anthropometry in body composition. An overview. Ann N Y Acad Sci 904:317-326

25. Wells JC, Fewtrell MS (2006) Measuring body composition. Arch Dis Child 91(7):612-617 